\title{
KEDALAMAN RENANG DAN WAKTU MAKAN IKAN ALBAKORA (Thunnus alalunga) DI SAMUDERA HINDIA SEBELAH SELATAN JAWA
}

\section{SWIMMING LAYER AND FEEDING PERIODICITY OF ALBACORE (Thunnus alalunga) IN THE INDIAN OCEAN SOUTH OFF JAVA}

\author{
Andi Bahtiar, Abram Barata dan Budi Nugraha \\ Peneliti pada Loka Penelitian Perikanan Tuna, Benoa-Bali \\ Teregistrasi I tanggal: 29 Januari 2014; Diterima setelah perbaikan tanggal: 25 Juli 2014; \\ Disetujui terbit tanggal: 04 Agustus 2014 \\ Email: andibhati@yahoo.com
}

\begin{abstract}
ABSTRAK
Albakora adalah salah satu spesies tuna yang berupa hasil tangkapan beku bernilai ekonomis tinggi bagi kapal-kapal rawai tuna. Penangkapan albakora di Samudera Hindia semakin kompetitif, sehingga setiap nahkoda dan nelayan kapal rawai tuna perlu memiliki pengetahuan mengenai tingkah laku ikan seperti kedalaman renang dan waktu makan. Penelitian ini dilakukan dengan metode observasi langsung di atas kapal rawai tuna yang berbasis di Benoa dan Palabuhanratu sebanyak 3 trip mulai Maret sampai Nopember 2013. Tujuan penelitian ini adalah untuk mengetahui kedalaman renang dan waktu makan albakora di Samudera Hindia. Hasil penelitian menunjukkan bahwa kedalaman renang albakora berdasarkan pengamatan data minilogger berada pada kisaran 57,04 - 325,46 m. Albakora lebih banyak tertangkap pada lapisan renang permukaan hingga pertengahan. Intensitas kebiasaan albakora mencari makanan dilakukan antara pukul 07:45 - 17:59, dengan frekuensi tertinggi aktif makan yaitu pada selang pukul 10:00 - 11:00. Untuk mendapatkan hasil tangkapan albakora yang berlimpah, maka nelayan rawai tuna perlu menggunakan metode penangkapan dengan perpaduan tipe rawai tuna permukaan dan pertengahan. Pengaturan waktu setting yang dimulai pagi hari dan waktu hauling mulai sore hari adalah waktu yang ideal dalam penangkapan albakora di Samudera Hindia.
\end{abstract}

Kata Kunci : Albakora, kedalaman renang, waktu makan, Samudera Hindia

\section{ABSTRACT}

Albacore is one of the tuna species and mostly landed as frozen catch on tuna longliner. Albacore fishing in Indian Ocean more competitive, so Fishermans or Fishing Masters of tuna longliner must have knowledge of tuna behavior such as swimming layer and feeding periodicity. Research was conducted with observation on board on tuna longliner based Benoa and Palabuhanratu, totally 3 trips during March until November 2013. The aim of research are to know of swimming layer and feeding periodicity of albacore in Indian Ocean. The results showed that the swimming layer of albacore based minilogger data are distributed at 57.04 to $325.46 \mathrm{~m}$ The results showed that the swimming layer of albacore at 57.04 to $325.46 \mathrm{~m}$. Albacore mostly catched in surface layer to middle in Indian Ocean. The feeding periodicity of albacore's are start from 7:45pm to 17:59pm, mostly active at 10pm to $11 \mathrm{pm}$. For the maximum catch of albacore's, every fisherman of tuna longline must have a good fishing tactics. The combination of surface and middle tuna longline types are the best fishing tactics to be applied. The setting of tuna longline begin morning and hauling begin afternoon are the best time for fishing of albacore in the Indian Ocean.

KEYWORDS : Albacore, swimming layer, feeding periodicity, Indian Ocean

\section{PENDAHULUAN}

Albakora (Thunnus alalunga) adalah salah satu spesies ikan tuna yang memiliki sifat peruaya jauh dan perenang yang handal karena memiliki kemampuan termoregulasi, tingkat metabolisme yang tinggi, memiliki kardiovaskular dan sistem peredaran darah atau pertukaran gas yang baik (IOTC, 2007). Sumber daya ikan albakora tersebar di seluruh perairan tropis dan sub tropis di Samudera Pasifik, Samudera Hindia dan Samudera Atlantik (FAO, 2010). Albakora yang tertangkap oleh kapal rawai tuna Indonesia yang beroperasi di Samudera Hindia dibekukan (frozen fish) dan diekspor ke beberapa negara seperti Swedia (53,4 \%), Italia (18,7\%), Polandia (17,8\%) dan Jepang (10\%) (Davis \& Andamari, 2003). Ikan ini juga dimanfaatkan sebagai bahan produk ikan kaleng tuna putih, sehingga di wilayah Samudera Pasifik ikan tersebut dikenal dengan nama "tombo" atau "tuna putih" (Collete \& Nauen, 1983).

Penangkapan tuna di Samudera Hindia semakin kompetitif, sehingga memerlukan teknik dan strategi penangkapan yang efisien. Penangkapan yang efisien memerlukan pengetahuan mengenai tingkah laku ikan tuna. 
Informasi tentang daerah penyebaran hubungannya dengan suhu perairan dan kedalaman renang (swimmimg layer) serta waktu makan (feeding periodicity) merupakan informasi yang berguna untuk mendukung keberhasilan penangkapan tuna. Keberhasilan penangkapan tuna akan mempengaruhi kegiatan industri perikanan tuna, terutama dalam hal meningkatkan pemasaran produk ikan baik untuk tujuan ekspor maupun lokal.

Barata et al. (2011a) melaporkan hasil penelitian tentang penyebaran ikan tuna di Samudera Hindia dengan menggunakan alat minilogger hasilnya menunjukkan bahwa albakora lebih banyak tertangkap pada kedalaman antara 85,7 - 124,7 m dengan suhu perairan antara 21,4 $26,4^{\circ} \mathrm{C}$. Dalam biologi perikanan, dikenal adanya feeding periodicity atau waktu kebiasaan ikan aktif mencari makanan selama 24 jam (Effendie, 2002). Gunarso (1998) menyebutkan bahwa jenis albakora umumnya mencari makan pada siang hari walau pada malam hari cukup aktif memburu mangsa. Data dan informasi tentang kedalaman renang dan waktu makan yang diperoleh dari kegiatan penelitian sangat berguna bagi para nahkoda atau fishing master kapal rawai tuna agar penangkapan ikan tuna dilakukan secara efektif dan efisien. Data dan informasi tersebut juga berguna bagi penyediaan informasi ilmiah tentang penyebaran ikan tuna di Indonesia terutana pada pertemuan internasional terkait pengelolaan sumber daya tuna di Samudera Hindia yang diadakan oleh "Indian. Ocean Tuna Commission" (IOTC) dan "Commission for the Conservation of Southern Bluefin Tuna" (CCSBT).

\section{BAHANDANMETODE \\ Pengumpulan dan Analisis Data}

Penelitian dilakukan sepanjang bulan Maret sampai Nopember 2013 melalui metode observasi langsung dengan cara mengikuti kegiatan selama 6 trip pada kapal rawai tuna yang berbasis di Benoa dan Palabuhanratu, di Samudera Hindia (Gambar 1). Data yang dikumpulkan meliputi aspek operasional penangkapan (spesifikasi kapal dan alat tangkap, waktu setting dan hauling), hasil tangkapan, ukuran panjang ikan, waktu makan dan kedalaman renang ikan tuna. Data tentang waktu makan tuna diperoleh dari informasi hook timer kemudian dicatat ke dalam program Microsoft Excel untuk di analisis menggunakan diagram. Data kedalaman renang diperoleh dari pengamatan menggunakan minilogger pada masingmasing kedalaman mata pancing. Pemindahan data dari minilogger menggunakan radio data pencil ke komputer dengan program WinMemo yang kemudian dipindahkan ke dalam program Microsoft Excel untuk di analisis dan kemudian disajikan dalam bentuk grafik.

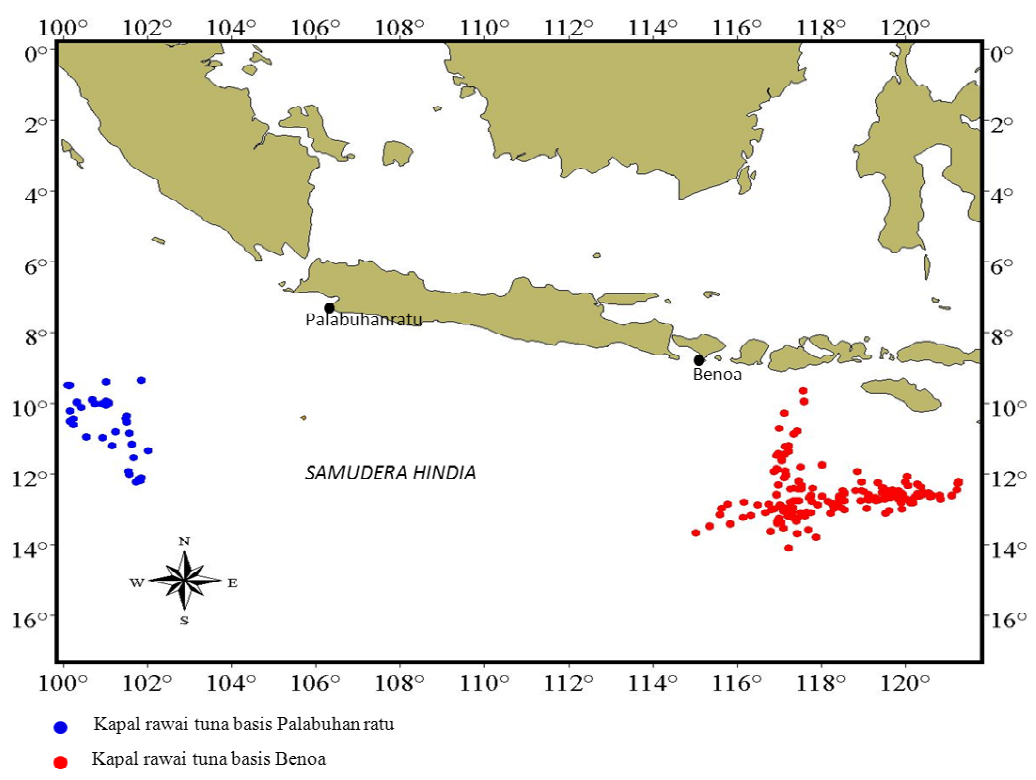

Gambar 1. Lokasi pengumpulan data selama observasi pada kapal rawai tuna.

Figure 1. Location of collecting data during the observation by tuna longline.

\section{Bahan dan Alat}

Bahan penelitian ini adalah ikan tuna albakora dan alat yag digunakan adalah rawai tuna, Alat yang digunakan dalam penelitian adalah kapal rawai tuna, Global Positioning System (GPS), 1 unit minilogger, meteran, 100 unit hook timer, kamera dan form isian data.
Rawai tuna yang dioperasikan menggunakan sistem blong yaitu Tali utama (main line) digulung didalam tong yang terbuat dari fyber dan tali cabang (branch line) berbahan monofilamen dengan diameter $3 \mathrm{~mm}$ dan $2 \mathrm{~mm}$, tali cabang mempunyai panjang antara 25,5 - 28,5 m. Satu set rawai tuna berjumlah 22 - 26 blong. Jumlah mata pancing antar pelampung bervariatif yaitu 11, 12 dan 16 
buah dengan ukuran mata pancing No. 4. Tali pelampung mempunyai panjang antara 28 - $31 \mathrm{~m}$. Jarak antar tali cabang antara $45-54 \mathrm{~m}$.

Alat hook timer yang digunakan adalah tipe HT 600. Alat ini memiliki ketahanan sampai kedalaman $600 \mathrm{~m}$. Dimensi alat mempunyai ukuran $8 \times 3 \mathrm{~cm}$, berat di udara 58 gr, berat di dalam air $47 \mathrm{gr}$, durasi waktu maksimum 29 jam 59 menit, memiliki automatic switch off of display setelah 5 hari, kekuatan baterai hingga 2 tahun dengan masa aktif menyala selama 840 jam, kerangka Clear Polycarbonate, dioperasikan pada suhu $0-40^{\circ} \mathrm{C}$ dan alat tersebut berfungsi pada hasil tangkapan ikan dengan minimum berat $3 \mathrm{~kg}$. Hook timer dipasang menjadi satu rangkaian dengan tali cabang yang nantinya dikaitkan langsung pada tali utama.

Alat minilogger yang digunakan adalah tipe SP2T1.200. Memiliki kemampuan merekam data pada kedalaman sampai $1.200 \mathrm{~m}$ dengan akurasi ketelitian 3,6 $\mathrm{m}$ dan daya resolusi mencapai $36 \mathrm{~cm}$. Sensor perekam suhu berkisar antara $-5-35^{\circ} \mathrm{C}$. Bahan terbuat dari plastik dan titanium dengan berat di dalam air mendekati 80 gr. Perlengkapan yang diperlukan untuk mengoperasikan minilogger ini meliputi: radio data pencil dan $\mathrm{PC}$ computer dilengkapi dengan RS port. Pada selang waktu tertentu minilogger akan merekam data suhu perairan dan kedalaman mata pancing. Minilogger dipasang pada ujung tali cabang, menggantikan mata pancing (hook). Gambar 2 menunjukkan posisi pemasangan minilogger dan hook timer pada rawai tuna.

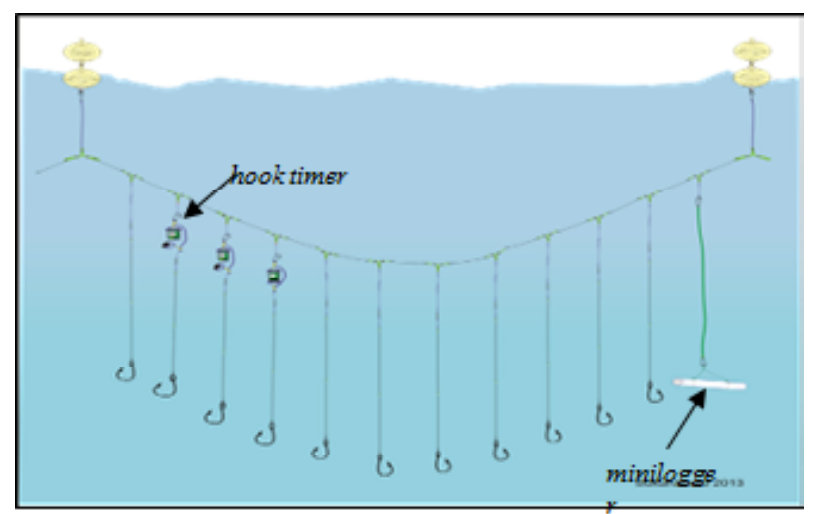

Gambar 2. Posisi pemasangan hook timer dan minilogger pada rawai tuna.

Figure 2. Position hook timer and minilogger on tuna longline.

\section{HASIL DAN BAHASAN \\ HASIL}

\section{Kedalaman Renang Albakora}

Kedalaman mata pancing merupakan salah satu faktor yang penting untuk mendapatkan hasil tangkapan maksimun, terutama pada perikanan rawai tuna. Hasil perekaman data minilogger untuk spesifikasi rawai tuna dengan jumlah 11 pancing tiap pelampung, menunjukkan nilai kedalaman mata pancing terdangkal yaitu $61,31 \mathrm{~m}$ dan kedalaman mata pancing terdalam yaitu 196,28 m (Gambar 3). Pada spesifikasi rawai tuna dengan jumlah 12 pancing tiap pelampung, menunjukkan nilai kedalaman mata pancing terdangkal yaitu $65,72 \mathrm{~m}$ dan kedalaman mata pancing terdalam yaitu $213,18 \mathrm{~m}$, sedangkan spesifikasi rawai tuna dengan jumlah 16 pancing tiap pelampung, menunjukkan nilai kedalaman mata pancing terdangkal yaitu 57,04 $\mathrm{m}$ dan kedalaman mata pancing terdalam yaitu $351,78 \mathrm{~m}$. Secara keseluruhan nilai kedalaman yang dihasilkan terlihat sesuai dengan pola kedalaman mata pancing. Setiap nomor pancing memperlihatkan nilai yang berbeda dan nilai kedalaman yang dihasilkan semakin besar seiring dengan semakin dalamnya letak mata pancing.

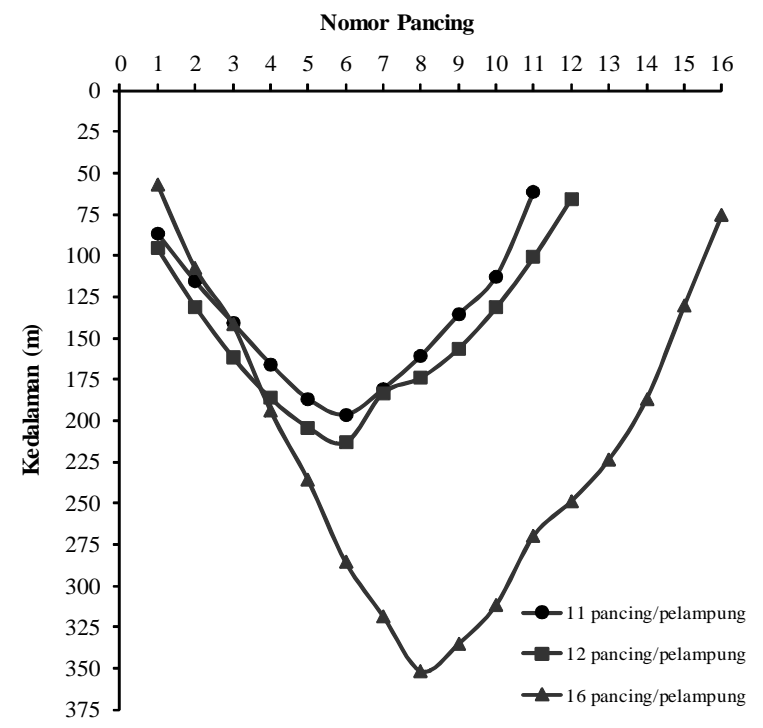

Gambar 3. Nilai kedalaman mata pancing berdasarkan perbedaan jumlah pancing tiap pelampung.

Figure 3. Hook depth value based on the difference in the amount of fishing each buoy.

Albakora lebih banyak tertangkap pada lapisan renang permukaan hingga pertengahan. Pada spesifikasi rawai tuna dengan jumlah 11 pancing tiap pelampung, albakora lebih banyak tertangkap pada posisi pancing nomor 3/9 dengan nilai rata-rata kedalaman yaitu $138,16 \mathrm{~m}$. Untuk spesifikasi rawai tuna dengan jumlah 12 pancing tiap pelampung, albakora lebih banyak tertangkap pada posisi pancing nomor 2/11 dengan nilai rata-rata kedalaman yaitu $115,89 \mathrm{~m}$, sedangkan pada spesifikasi rawai tuna dengan jumlah 16 pancing tiap pelampung, albakora lebih banyak tertangkap pada posisi pancing nomor $1 / 16$ dengan nilai rata-rata kedalaman yaitu $66,11 \mathrm{~m}$. Secara keseluruhan kedalaman renang albakora berdasarkan pengamatan data 
minilogger dan hasil tangkapan pada setiap nomor pancing berada pada kisaran 57,04 - 325,46 m. Spesifikasi rawai tuna dengan jumlah 16 pancing tiap pelampung merupakan tipe rawai tuna dalam dibandingkan tipe rawai tuna lainnya, namun albakora tidak tertangkap pada posisi pancing nomor 8/9 yang merupakan mata pancing terdalam.

\section{Waktu Makan Albakora}

Hook timer merupakan alat yang digunakan untuk mengetahui waktu tertangkapnya seekor ikan pada pancing dan memberikan informasi waktu makan ikan atau feeding periodicity. Cara kerja hook timer adalah pada saat ikan tertangkap, ikan tersebut berusaha melepaskan diri dari pancing sehingga penutup magnet hook timer akan terlepas dan mulai terekam waktu pada alat tersebut. Kemudian saat alat ditarik oleh line hauler, waktu terus terekam sampai ke dek kapal sehingga dapat diketahui informasi waktu makan ikan. Intensitas kebiasaan albakora mencari makanan dilakukan antara pukul 08:00 sampai pukul 18:00 (Gambar 4). Frekuensi tertinggi albakora aktif makan yaitu pada selang pukul 10:00-11:00. Waktu makan rata-rata albakora adalah pada pukul 11:45.

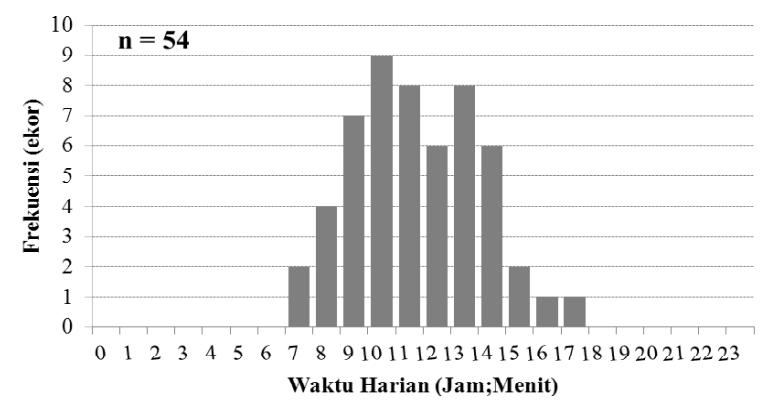

Gambar 4. Waktu makan albakora di Samudera Hindia. Figure 4. Eating time of albacore at Indian Ocean.

\section{BAHASAN}

Penyebaran ikan tuna di laut ditentukan oleh dua faktor yaitu faktor internal dan faktor eksternal (Nakamura, 1969; Brill, 1994; Sumadhiharga, 2009). Faktor internal meliputi jenis (genetik), umur, ukuran, dan tingkah laku ikan. Faktor eksternal merupakan faktor lingkungan, di antaranya adalah parameter oseanografis seperti suhu, salinitas, densitas, kedalaman lapisan thermoklin, arus, sirkulasi massa air, oksigen dan kelimpahan makanan. Barata et al. (2011a) melaporkan hasil penelitian di Samudera Hindia menggunakan pengukuran minilogger menunjukkan bahwa albakora lebih banyak tertangkap pada kedalaman 85,73 - 124,74 m. Hasil penelitian Nugraha \& Triharyuni (2009), albakora banyak tertangkap pada kedalaman antara 150 - 200 m di Samudera Hindia. Pranata (2013) melaporkan hasil penelitian kedalaman albakora berdasarkan perhitungan rumus Yoshihara berada pada kisaran kedalaman antara $64-232 \mathrm{~m}$. Hasil penelitian Chavance (2005) di pantai barat New Caledonia menunjukkan bahwa albakora tertangkap pada kedalaman $100-410 \mathrm{~m}$. Kedalaman letak mata pancing rawai tuna ditentukan oleh panjang tali pelampung, panjang tali cabang, panjang tali utama, jumlah pancing tiap pelampung dan koefisien kelengkungan antar tali cabang. Hal inilah yang menyebabkan beberapa perbedaan kedalaman renang albakora.

Kedalaman renang albakora sebagian besar berada pada lapisan permukaan hingga pertengahan. Beberapa diantaranya dapat mencapai lapisan lebih dalam. Ikan tuna berukuran besar berada di lapisan dalam dengan gerombolan yang lebih sedikit jumlahnya, sedangkan yang berukuran lebih kecil terdapat di lapisan permukaan dalam jumlah besar. Barata et al. (2011a) melaporkan $64 \%$ dari albakora berukuran $>100 \mathrm{~cm}$ pada kedalaman antara 85,7124,7 m. Hasil penelitian Chen et al. (2005) menunjukkan sebaran albakora immature berada pada lapisan renang permukaan, sedangkan albakora berukuran mature lebih banyak tertangkap pada lapisan pertengahan. Rawai tuna yang dioperasikan oleh kapal-kapal rawai tuna berbasis di Benoa dibagi menjadi tiga tipe, yaitu tipe yang bersifat permukaan (surface tuna longline), pertengahan (middle tuna longline) dan dalam (deep longline) (Barata et al., 2011a). Menurut Irianto et al. (2013), tipe rawai tuna permukaan ditandai oleh 5 buah pancing antar pelampung) beroperasi pada kisaran kedalaman antara 100 - 175 m, tipe rawai tuna pertengahan (12 pancing antar pelampung) pada kisaran kedalaman 125 - $350 \mathrm{~m}$ dan tipe rawai tuna dalam (18 pancing antar pelampung) pada kisaran kedalaman 150-450 m. Untuk memburu albakora sesuai dengan habitatnya, maka perpaduan antara konstruksi rawai tuna bersifat permukaan dan pertengahan merupakan taktik penangkapan yang ideal.

Periode waktu makan (Feeding periodicity) berkaitan dengan distribusi dan konsentrasi makanan serta kondisi lingkungan perairan di sekitarnya. Kondisi lingkungan perairan yang tercemar dapat menyebabkan feeding periodicity berubah-ubah, bahkan dapat meyebabkan terhentinya pengambilan makanan (Effendie, 2002). Ikan tuna bermigrasi secara bergerombol dengan tujuan mencari makan ke suatu daerah perairan, apabila di perairan tersebut tampak terdapat sumber makanan. Akan tetapi, bila distribusi dan konsentrasi makanannya habis, ikan tuna akan berpindah ke tempat lain untuk mencari mangsanya.

Selama observasi, sebagian besar kapal-kapal rawai tuna melakukan setting mulai pagi hari, tetapi ada juga yang melakukan setting mulai sore hari saat kondisi bulan terang. Albakora memiliki intensitas mencari makanan pada pagi hingga siang hari dan terjadi 1 kali periodik dalam 24 jam. Hal ini menandakan albakora tergolong ikan diurnal 
atau ikan yang aktif mencari makanan pada siang hari hingga menjelang matahari tenggelam. Aktifitas ikan diurnal mempunyai gerakan yang cepat, aktif dan bermigrasi dalam area yang luas (Effendi, 2002). Gunarso (1998), menyebutkan bahwa albakora mencari makan pada siang hari walau pada malam hari cukup aktif memburu mangsa.

Musyl et al. (2003), menyatakan bahwa jumlah pigmen warna pada indera penglihatan tuna berpengaruh terhadap pola kebiasaan tuna dalam mencari makanan. Pigmen warna yang terbatas menyebabkan kebiasaan mencari makanan terkonsentrasi pada lingkungan perairan yang jernih atau terang. Faktor cahaya matahari pada waktu siang hari yang menembus lapisan perairan juga mempengaruhi kemampuan penglihatan ikan dalam mencari makanan. Dalam keadaan perairan yang keruh atau intensitas cahaya matahari yang masuk tidak banyak, kemampuan daya penglihatan ikan pada suatu objek yang terdapat di dalam air akan berkurang. Umumnya semua jenis tuna dapat menyesuaikan kemampuan indera penglihatan baik pada siang hari dan malam hari, tergantung pada pengaturan fungsi sel cone dan rod yang terdapat di dalam retina mata ikan (Masuma et al., 2001). Jenis ikan yang aktif pada siang hari, umumnya mempunyai cone yang tersusun dalam bentuk empat persegí. Ikanikan yang memiliki cone bentuk seperti ini adalah jenis ikan yang intensif sekali menggunakan indera penglihatnya dan termasuk ikan yang aktif memburu mangsa. Ikan tuna tidak selektif dalam mencari jenis makanan yang disukai (Barata et al., 2011b). Faktor-faktor yang mempengaruhi jenis dan jumlah makanan yang dikonsumsi oleh suatu spesies ikan adalah umur, tempat dan waktu (Effendie, 2002). Aktifitas ikan diurnal mempunyai gerakan yang cepat, aktif dan bermigrasi dalam area yang luas.

\section{KESIMPULAN}

Kedalaman renang ikan albakora (Thunnus alalunga) di Samudera Hindia sebelah Selatan Jawa berada pada kisaran kedalaman antara 57 - $325 \mathrm{~m}$. Albakora memiliki pola satu kali periode waktu makan dalam 24 jam dan termasuk kelompok ikan diurnal, waktu makan biasanya pada siang hari sekitar pukul 12.00. Untuk mendapatkan hasil tangkapan albakora yang berlimpah, maka nelayan rawai tuna perlu menggunakan metode penangkapan secara vertikal yaitu perpaduan antara konstruksi rawai tuna permukaan dan pertengahan. Pengaturan waktu penangkapan tuna (setting) pada pagi hari dan waktu penarikan (hauling) sore hari adalah waktu yang ideal dalam memburu albakora di Samudera Hindia.

\section{PERSANTUNAN}

Tulisan ini merupakan kontribusi dari kegiatan hasil penelitian kedalaman renang (swimming layer) dan waktu makan (feeding periodicity) tuna di Samudera Hindia, tahun anggaran 2013 pada Loka Penelitian Perikanan Tuna. Penulis mengucapkan terima kasih kepada para observer di Loka Penelitian Perikanan Tuna Benoa yang telah membantu dalam pengumpulan data dengan obervasi langsung di kapal rawai tuna.

\section{DAFTAR PUSTAKA}

Barata, A., D. Novianto \& A. Bahtiar. 2011a. Sebaran ikan tuna berdasarkan suhu dan kedalaman di Samudera Hindia. Jurnal Ilmu Kelautan Indonesia. Universitas Diponegoro. Semarang. 16 (3): 165-170.

Barata, A., A. Bahtiar \& H. Hartaty. 2011b. Pengaruh perbedaan umpan dan waktu setting rawai tuna terhadap hasil tangkapan tuna di Samudera Hindia. Jurnal Penelitian Perikanan Indonesia. Pusat Penelitian Pengelolaan Perikanan dan Konservasi Sumber Daya Ikan. Jakarta. 17 (2): 133-138.

Brill, R., 1994. Areview of temperature and oxygen tolerance studies of tunas pertinent to fisheries oceanography, movements models and stock assessments. Fish. Oceanography. 3 (3): 204-216.

Chavance, P. 2005. Depth, temperature and capture time of longline targeted fish in New Caledonia: Results of a one year study. Paper for $1^{\text {st }}$ Meeting of the Scientific Committee of the Western and Central Pacific Fisheries Commission. WCPFC - SC1. Noumea, New Caledonia 8-19 August 2005. www.spc.int/oceanfish/ diakses pada tanggal 3 April 2008.

Chen, I.C., P.F. Lee \& W.N. Tseng. 2005. Distribution of albacore (Thunnus alalunga) in the Indian Ocean and its relation to environmental factor. Fisheries Oceanography. 71-80.

Collette, B.B. \& Nauen, C.E. 1983. FAO species catalogue. Vol. 2. Scombrids of the world. An annotated and illustrated catalogue of tunas, mackerels, bonitos and related species known to date. Food and Agriculture organization of the United Nations (FAO) Fisheries Synopsis. 2 (125).

Davis, T. L. O. \& R. Andamari. 2003. Analysis of 2001 dinas export packing list data by species, product and destination. CCSBT Indonesian Catch Monitoring Review, Queenstown, New Zealand, 10-11 April 2003. CCSBT-ICM/0304/7.

Effendie, M.I. 2002. Biologi Perikanan. Yayasan Pustaka Nusantara. Yogyakarta. 
FAO. 2010. Tuna resources. http://www.fao.org/fishery/ topic/12251/en. Diunduh tanggal 18 Juli 2013.

Gunarso, W. 1998. Tingkah laku ikan dan perikanan pancing. Diktat Kuliah. Laboratorium Tingkah Laku Ikan. Fakultas Perikanan dan Ilmu Kelautan. Institut Pertanian Bogor. 119pp.

IOTC. 2007. Executive summaries of the status of the major Indian Ocean tunas and billfish (albacore, bigeye, yellowfin, skipjack, and swordfish). Executive summary of the status of the albacore tuna resource. IOTC2007-SC-03 [E]. 46 pp.

Irianto, H. E., Wudianto, F. Satria \& B. Nugraha. 2013. Tropical Tuna Fisheries in the Indian Ocean of Indonesia. IOTC-2013-WPTT15-20. 14 p.

Masuma, S., G. Kawamura, N. Tezuka, M. Koiso \& K. Namba. 2001. Retinomotor responses of juvenile bluefin tuna Thunnus thynnus. Fisheries Sci. 67:228-231.

Musyl, M.K., R.W. Brill, C.H. Boggs, D.S. Curran, T.K. Kazama \& M.P. Seki. 2003. Vertical movements of bigeye tuna (Thunnusobesus) associated with islands, bouys and seamounts near the main Hawaiian Islands from archival tagging data. Fisheries Oceanography. 12:152-169.
Nugraha, B. \& S. Triharyuni. 2009. Pengaruh suhu dan kedalaman mata pancing rawai tuna (tuna longline) terhadap hasil tangkapan tuna di Samudera Hindia. Jurnal Penelitian Perikanan Indonesia. Pusat Riset Perikanan Tangkap. Balai Riset Perikanan Laut. Departemen Kelautan dan Perikanan. 15. (3) : 239-247.

Nakamura, H. 1969. Tuna Distribution and Migration. Fishing News Book Ltd. London.

Pranata, S. A. 2013. Kedalaman lapisan renang tuna (Thunnus sp.) yang tertangkap oleh rawai tuna di Samudera Hindia. Skripsi. Fakultas Perikanan dan Ilmu Kelautan. Institut Pertanian Bogor.

Suharto. 1995. Pengaruh kedalaman mata pancing rawai tuna terhadap hasil tangkapan (Percobaan orientasi dengan KM. Madidihang di Samudera Hindia Sebelah Barat Sumatera). Skripsi. Jurusan Pemanfaatan Sumberdaya Perikanan. Fakultas Perikanan. Institut Pertanian Bogor: 78 p.

Sumadhiharga, O.K. 2009. Ikan tuna. Pusat Penelitian Oseanografi. Lembaga Ilmu Pengetahuan Indonesia. Jakarta: 129 p. 